\title{
Comunicación
}

\section{AISLAMIENTO BACTERIANO EN CASOS DE OTITIS CANINA Y SU SUSCEPTIBILIDAD ANTIBIÓTICA}

\author{
BaCterial Isolation in Canine Ear Infections ANd Its ANTimicrobial \\ SUSCEPTIBILITY
}

Ricardo Sánchez Ch. ${ }^{1}$, Sonia Calle E. ${ }^{1,2}$, Néstor Falcón P. ${ }^{3,4}$, Chris Pinto J. ${ }^{1}$

\section{Resumen}

\begin{abstract}
El objetivo de este estudio fue determinar la frecuencia de casos de otitis bacteriana en canes, las bacterias involucradas y su susceptibilidad a los antibacterianos, en base a muestras procesadas en un laboratorio de microbiología especializado en el campo veterinario en el periodo 2001-2006. Se emplearon 429 fichas de laboratorio. La bacteria de mayor frecuencia fue el Staphylococcus intermedius (27.7\%), pero hubo otros agentes de importancia como Pseudomonas aeruginosa, Streptococcus sp. y Staphylococcus $\mathrm{sp}$. Las infecciones óticas fueron mayormente monomicrobianas (63.6\%). En las pruebas de susceptibilidad por el método de Kirby-Bauer se encontró el mayor nivel de susceptibilidad de las bacterias a las quinolonas, aminoglucósidos, cefalosporinas y penicilinas combinadas con inhibidores de las betalactamasas; mientras que las penicilinas, sulfas, tetraciclinas, lincosamidas y macrólidos fueron los antimicrobianos de menor efectividad.
\end{abstract}

Palabras clave: otitis, susceptibilidad, bacterias, caninos

\section{Abstract}

The objective of the study was to determine the frequency of bacterial otitis cases in dogs, the bacteria involved in the infection and the bacterial susceptibility to antibiotics in samples processed during 2001-2006 in a bacteriology laboratory specialized in the veterinary field. A total of 429 laboratory records were used. The most frequent isolated bacteria was Staphylococcus intermedius (27.7\%), but other important species were also found (Pseudomonas aeruginosa, Streptococcus sp. and Staphylococcus sp). Ear infections were mostly due to a single bacteria species (63.6\%). In susceptibility test using the Kirby-Bauer method the quinolones, aminoglycosides, cephalosporins, and

\footnotetext{
${ }^{1}$ Laboratorio de Microbiología y Parasitología Veterinaria, ${ }^{3}$ Laboratorio de Medicina Veterinaria Preventiva, Facultad de Medicina Veterinaria, Universidad Nacional Mayor de San Marcos, Lima

${ }^{2}$ E-mail: calleson@gmail.com

${ }^{4}$ Dirección actual: Facultad de Veterinaria y Zootecnia, Universidad Peruana Cayetano Heredia, Lima
} 
penicillins combined with inhibitors of betalactamics showed better antimicrobial effect, while bacteria species showed high resistance to penicillin, sulpha, tetracyclines, macrolides and lincosamides.

Key words: otitis, susceptibility, bacteria, canine

La otitis es una enfermedad de etiología multifactorial que afecta a los caninos, y representa entre 5 a $20 \%$ de la práctica veterinaria diaria. Esta patología se encuentra asociada mayormente a infecciones causadas por bacterias y levaduras, que muchas veces no responden a los tratamientos con antibióticos (Cole et al., 1998; Taibo, 2003). La estructura anatómica de la oreja del perro predispone la presentación de esta patología, ya que la forma del cartílago auricular crea un ambiente oscuro y de poca ventilación que favorece la proliferación de bacterias (Dyce, 1999; Craig, 2000). Asimismo, la edad y la raza son factores asociados a los cuadros de otitis.

La otitis puede ser externa, media e interna. La otitis externa es la más importante y se presenta usualmente asociada a la otitis media (Helton y Werner, 2006). Esta última puede originarse, como en el caso de la otitis externa, por una infección respiratoria o por vía sanguínea (Taibo, 2003; Oliveira et al., 2005). La otitis interna se presenta como una extensión de la otitis media y afecta las funciones vestibular y coclear del oído (Taibo, 2003). El diagnóstico de las otitis es de tipo clínico (Carlotti, 1991; Taibo, 2003), y en algunos casos se apoya en un examen citológico (Chávez, 1994; Alpaca, 1995), mientras que para casos crónicos están indicadas las pruebas de laboratorio como el cultivo y la prueba de susceptibilidad bacteriana (Grant, 1997; Craig, 2000).

En las pruebas de laboratorio, se logra aislar bacterias en el $92 \%$ de muestras colectadas en perros con signos clínicos de otitis (Oliveira et al., 2005). El Staphylococcus intermedius es la bacteria que se logra aislar con mayor frecuencia. Esta bacteria facilita el ingreso de otros microorganismos luego de evadir a la fagocitosis por medio de sus fac- tores de virulencia (Koneman et al., 1992). Pseudomonas sp. y Proteus mirabilis suelen presentarse en casos crónicos y son conocidas por su resistencia a diversos antibióticos (Kowalsky, 1988; Kirk y Bonagura, 1997; Morgan et al., 2004).

La terapia tópica es una buena elección puesto que se alcanzan altas concentraciones de los medicamentos con los menores efectos sistémicos, mientras que la terapia sistémica puede ser de utilidad en tratamientos prolongados (Taibo, 2003; Helton y Werner, 2006). Debido a la amplia gama de antibióticos que se encuentra en el mercado, el médico veterinario debe seleccionar la terapia más adecuada, específica y simple (Carlotti, 1991; Craig, 2000) y evitar que la infección se extienda al oído medio e interno (Merchant, 1997; Craig, 2000). Las quinolonas, cefalosporinas, aminoglucósidos y penicilinas combinadas son los fármacos con mayor eficacia (Colombini et al., 2000; Taibo, 2003; Oliveira et al., 2005).

El objetivo del presente estudio fue determinar la frecuencia de otitis bacteriana en canes, las bacterias involucradas y su susceptibilidad a los antibacterianos en base a muestras procesadas en el Laboratorio de Microbiología de la Facultad de Medicina Veterinaria (FMV) de la Universidad Nacional Mayor de San Marcos (UNMSM), durante el periodo 2001 al 2006. Se trabajó con 429 fichas de laboratorio de caninos con diagnóstico clínico de otitis, que representan muestras de hisopado del canal auditivo externo remitidas al laboratorio para aislamiento bacteriano y prueba de susceptibilidad. Las muestras fueron remitidas por la Clínica de Animales Menores de la FMV-UNMSM y de clínicas privadas de la zona de Lima para la identificación de la bacteria y posibles tratamientos con antibióticos. 
Cuadro 1. Distribución mensual, estacional y anual de casos de otitis bacteriana canina procesados en el Laboratorio de Microbiología de la Facultad de Medicina Veterinaria-UNMSM, en el periodo 2001-2006

\begin{tabular}{|c|c|c|c|c|c|c|c|c|c|}
\hline \multirow{2}{*}{ Estación } & \multirow{2}{*}{ Mes } & \multicolumn{2}{|c|}{ Total } & \multicolumn{6}{|c|}{ Años } \\
\hline & & N. ${ }^{\circ}$ & $\%$ & 2001 & 2002 & 2003 & 2004 & 2005 & 2006 \\
\hline \multirow{3}{*}{ Verano } & Ene & 58 & 13.5 & 22 & 17 & 12 & 1 & 3 & 3 \\
\hline & Feb & 35 & 8.2 & 12 & 10 & 4 & 0 & 7 & 2 \\
\hline & Mar & 31 & 7.2 & 15 & 7 & 3 & 3 & 2 & 1 \\
\hline \multirow{3}{*}{ Otoño } & Abr & 34 & 7.9 & 18 & 7 & 5 & 2 & 2 & 0 \\
\hline & May & 38 & 8.9 & 16 & 4 & 7 & 6 & 3 & 2 \\
\hline & Jun & 36 & 8.4 & 13 & 6 & 2 & 6 & 5 & 4 \\
\hline \multirow{3}{*}{ Invierno } & Jul & 30 & 7.0 & 15 & 2 & 3 & 4 & 5 & 1 \\
\hline & Ago & 33 & 7.7 & 11 & 10 & 3 & 4 & 4 & 1 \\
\hline & Set & 35 & 8.2 & 19 & 5 & 6 & 1 & 2 & 2 \\
\hline \multirow{3}{*}{ Primavera } & Oct & 33 & 7.7 & 14 & 8 & 5 & 1 & 3 & 2 \\
\hline & Nov & 41 & 9.6 & 16 & 9 & 6 & 5 & 2 & 3 \\
\hline & Dic & 25 & 5.8 & 12 & 2 & 3 & 0 & 3 & 5 \\
\hline Total & & 429 & 100 & 183 & 87 & 59 & 33 & 41 & 26 \\
\hline
\end{tabular}

El manejo rutinario de las muestras recibidas por el laboratorio fue el siguiente: las muestras se procesan siguiendo los protocolos establecidos en el laboratorio, se siembran en un medio selectivo (Agar Mc Conkey) y un medio general (Agar Sangre: Agar tripticasa soya más 5\% de sangre de ovino desfibrinada) y se incuban durante 24 horas a $37^{\circ} \mathrm{C}$. Luego se procede a las técnicas de coloración de apoyo (tinción Gram) para definir las pruebas bioquímicas que lleven al diagnóstico definitivo de la bacteria. Asimismo, se realiza la prueba de susceptibilidad de acuerdo al método de Kirby-Bauer (Koneman et al., 1992), midiendo el halo de inhibición bacteriana para determinar la susceptibilidad o resistencia.

Se obtuvo de cada ficha de laboratorio los resultados de aislamiento bacteriano, número de microorganismos aislados y niveles de susceptibilidad bacteriana a los antibióticos evaluados en la prueba de susceptibilidad. Se determinó la frecuencia mensual, estacional y anual de recepción de hisopados de secreción ótica canina con sospecha de otitis bacteriana y de las especies bacterianas.

La frecuencia de casos de otitis canina bacteriana se muestra en el Cuadro 1. El marcado descenso en la recepción de muestras por año se debió a una derivación de muestras a laboratorios privados de reciente creación en la zona de Lima; sin embargo, la distribución estacional fue homogénea con una ligera elevación en el verano (Invierno: 22.8\%; Primavera: $21.1 \%$; Verano: $28.9 \%$; y Otoño: $25.2 \%$ ). La época del año no fue importante en la presentación de casos, salvo una disminución en diciembre y un aumento en enero que podría estar asociado a las actividades de los dueños de las mascotas en el mes festivo. 
Cuadro 2. Frecuencia de bacterias aisladas en hisopados del canal auditivo externo de canes con otitis en el periodo 2001-2006

\begin{tabular}{lcc}
\hline & \multicolumn{2}{c}{ Total $^{1}$} \\
\cline { 2 - 3 } & N. & $\%$ \\
\hline Staphylococcus intermedius & 168 & 27.72 \\
Pseudomona aeruginosa & 120 & 19.80 \\
Staphylococcus sp. & 102 & 16.83 \\
Streptococcus sp. & 57 & 9.41 \\
Echerichia. coli & 43 & 7.10 \\
Bacillus sp. & 29 & 4.79 \\
Proteus sp. & 24 & 3.96 \\
Staphylococcus epidermidis & 21 & 3.47 \\
Staphylococcus aureus & 14 & 2.31 \\
Proteus mirabilis & 10 & 1.65 \\
Proteus vulgaris & 7 & 1.16 \\
Otras bacterias & 11 & 1.82 \\
\hline Total de agentes aislados & 606 & 100.00 \\
\hline
\end{tabular}

${ }^{1}$ En base a 429 muestras

El Staphylococcus intermedius fue la bacteria de mayor frecuencia en los aislamientos $(27.7 \%)$. Otros agentes de importancia fueron la Pseudomonas aeruginosa (19.8\%) y el Staphylococcus sp. (16.8\%) (Cuadro 2). Estos resultados coinciden con otros reportes (Lilebaum et al., 2000; Oliveira et al., 2005; Fernández et al., 2006). En el $63.6 \%$ de casos clínicos se aisló un solo agente bacteriano, mientras que los casos con 2, 3 y 4 especies de bacterias fue de 31.9, 4.2 y $0.2 \%$, aunque se dispone de reportes disímiles (Oliveira et al., 2005; Pundir, 2007). Esto puede estar relacionado al curso de la enfermedad y el momento de la toma de la muestra; además, es importante determinar las especies presentes en la infección ya que una infección polimicrobiana puede hacer el tratamiento más complejo.

El mayor nivel de susceptibilidad bacteriana a los antibióticos se presentó con la gentamicina $(76.9 \%)$, ciprofloxacina
(76.6\%), norfloxacina (75.8\%), enrofloxacina (62.5\%) y amoxicilina combinada con el ácido clavulánico (54.5\%), mientras que los antibióticos con mayores niveles de resistencia bacteriana fueron la estreptomicina (84.6\%), penicilina (79.8\%), ácido nalidíxico (73.9\%) y oxitetraciclina (73.1\%) (Cuadro 3). Los antibióticos con mayor susceptibilidad bacteriana son los antibióticos de elección para el tratamiento de la otitis canina. Estos resultados son similares a los de Oliveira et al. (2005), quienes demostraron alta susceptibilidad bacteriana a las quinolonas, minoglucósidos, cefalosporinas y betalactámicos combinados con inhibidores de betalactamasas.

El presente estudio demuestra la necesidad que tiene el clínico de utilizar el apoyo del laboratorio bacteriológico para definir el tratamiento específico a cada caso de otitis canina. 
Cuadro 3. Resultados porcentuales de la prueba de susceptibilidad en muestras de otitis bacteriana canina procesadas en el Laboratorio de Microbiología de la Facultad de Medicina Veterinaria-UNMSM, en el periodo 2001-2006 $(\mathrm{n}=3078$ discos empleados)

\begin{tabular}{|c|c|c|c|c|c|}
\hline \multirow{2}{*}{$\begin{array}{l}\text { Familia de } \\
\text { antibióticos }\end{array}$} & \multirow[t]{2}{*}{ Antibióticos } & \multicolumn{3}{|c|}{$\begin{array}{c}\text { Susceptibilidad } \\
(\%)\end{array}$} & \multirow{2}{*}{$\begin{array}{l}\text { Muestras } \\
\text { (n) }\end{array}$} \\
\hline & & Susceptible & Intermedio & Resistente & \\
\hline \multirow[t]{4}{*}{ Aminoglucósidos } & & 66.1 & 9.4 & 24.5 & 513 \\
\hline & Gentamicina & 76.9 & 5.6 & 17.5 & 337 \\
\hline & Neomicina & 50.0 & 21.6 & 28.4 & 116 \\
\hline & Kanamicina & 36.7 & 6.7 & 56.7 & 60 \\
\hline \multirow[t]{5}{*}{ Penicilinas } & & 38.5 & 4.1 & 57.4 & 789 \\
\hline & Penicilinas & 17.7 & 2.5 & 79.7 & 79 \\
\hline & Amoxicilina & 37.9 & 1.6 & 60.5 & 253 \\
\hline & Ampicilina & 25.4 & 1.6 & 73.0 & 189 \\
\hline & $\begin{array}{l}\text { Amoxicilina + } \\
\text { Ac. clavulánico }\end{array}$ & 54.5 & 8.6 & 36.9 & 268 \\
\hline \multirow[t]{4}{*}{ Quinolonas } & & 70.4 & 6.8 & 20.0 & 456 \\
\hline & Ciprofloxacina & 76.6 & 6.7 & 16.7 & 282 \\
\hline & Enrofloxacina & 62.5 & 7.8 & 29.7 & 128 \\
\hline & Norfloxacina & 75.8 & 6.1 & 18.2 & 33 \\
\hline \multirow[t]{7}{*}{ Tetraciclinas } & & 29.9 & 7.4 & 62.7 & 419 \\
\hline & Tetraciclina & 42.3 & 21.2 & 36.5 & 52 \\
\hline & Oxitetraciclina & 25.0 & 1.9 & 73.1 & 108 \\
\hline & Doxiciclina & 29.5 & 7.5 & 63.0 & 146 \\
\hline & Dicloxaciclina & 20.5 & 13.6 & 65.9 & 44 \\
\hline & Oxaciclina & 29.1 & 0.0 & 70.9 & 55 \\
\hline & Cloxaciclina & 57.1 & 7.1 & 35.7 & 14 \\
\hline \multirow[t]{4}{*}{ Cefalosporinas } & & 52.9 & 5.1 & 42.0 & 367 \\
\hline & Cefalexina & 51.9 & 6.0 & 42.1 & 266 \\
\hline & Cefalotina & 51.6 & 3.1 & 45.3 & 64 \\
\hline & Otras cefalosporinas & 62.2 & 2.7 & 35.1 & 37 \\
\hline \multicolumn{2}{|c|}{ Lincosamidas y Macrólidos } & 37.9 & 3.4 & 59.4 & 178 \\
\hline & Lincomicina & 41.9 & 1.2 & 57.0 & 86 \\
\hline & Clindamicina & 32.0 & 2.0 & 66.0 & 50 \\
\hline & Estreptomicina & 15.4 & 0.0 & 84.6 & 13 \\
\hline & Dihidroestreptomicina & 55.6 & 11.1 & 33.3 & 18 \\
\hline & Eritromicina & 18.2 & 18.2 & 63.6 & 11 \\
\hline \multirow[t]{3}{*}{ Sulfas } & & 27.4 & 7.8 & 64.8 & 144 \\
\hline & Sulfa-Trimetropin & 33.5 & 4.5 & 62.2 & 111 \\
\hline & Trimetropin & 6.5 & 19.4 & 74.2 & 31 \\
\hline \multirow[t]{3}{*}{ Nitrofuranos } & & 45.7 & 4.3 & 50.0 & 116 \\
\hline & Nitrofurantoína & 61.8 & 4.4 & 33.8 & 68 \\
\hline & Furazolidona & 22.9 & 4.2 & 72.9 & 48 \\
\hline Fosfonatos & Fosfomicina & 18.2 & 18.2 & 63.6 & 22 \\
\hline Otros antibióticos & & 43.7 & 9.2 & 47.1 & 42 \\
\hline Total & & 42.9 & 9.5 & 47.6 & 42 \\
\hline
\end{tabular}




\section{Literatura Citada}

1. Alpaca C. 1995. Otitis por Malassezia pachidermatis en caninos de orejas erectas vs caninos de orejas caídas. Tesis de Médico Veterinario. Lima: Facultad de Medicina Veterinaria, Univ Nacional Mayor de San Marcos. 31 p.

2. Carlotti D. 1991. Diagnosis and medical treatment of otitis externa in dogs and cats. J South Am Pract 32(5): 394-400.

3. Chávez R. 1994. Frecuencia de la Malassezia pachidermatis en casos de otitis externa en caninos de la ciudad de Lima. Tesis de Médico Veterinario. Lima: Facultad de Medicina Veterinaria, Univ Nacional Mayor de San Marcos. 38 p.

4. Cole L, Kwochka K, Kowaslki J, Hillier A. 1998. Microbial flora and antimicrobial susceptibility patterns of isolated pathogens from the horizontal ear canal and middle ear in dogs with otitis media. JAVMA 212: 534-538.

5. Colombini S, Merchant S, Hosgood G. 2000. Microbial flora and antimicrobial susceptibility patterns from dogs with otitis media. Rev Vet Dermatol 11: 235-239.

6. Craig E. 2000. Enfermedades infecciosas en perros y gatos. $2^{\mathrm{a}}$ ed. México DF: McGraw-Hill Interamericana. $1014 \mathrm{p}$.

7. Dyce K. 1999. Anatomía veterinaria. $2^{\mathrm{a}}$ ed. México DF: McGraw-Hill Interamericana. $952 \mathrm{p}$.

8. Fernández G, Barboza G, Villalobos A, Parra O, Finol G, Ramírez R. 2006. Isolation and identification of microorganisms present in 53 dogs suffering otitis externa. Rev Cient Fac Cien Vet, Maracaibo 12(1): 23-30.

9. Grant D. 1997. Enfermedades de la piel en perros y gatos. $2^{\mathrm{a}}$ ed. México DF: McGraw-Hill Interamericana. 203 p.

10. Helton K, Werner A. 2006. La consulta veterinaria en 5 minutos: Dermatolo- gía de animales pequeños. Buenos Aires: Ed. Intermédica. 752 p.

11. Kirk R, Bonagura J. 1997. Terapéutica veterinaria de pequeños animales. $12^{\mathrm{a}}$ ed. México DF: McGraw-Hill Interamericana. $1638 \mathrm{p}$.

12. Koneman E, Allen S, Janda W, Schrewenberger P, Winn W. 1992. Diagnosis microbiological - atlases. $4^{\text {th }}$ ed. Philadelphia: JB Lippincott. 1154 p.

13. Kowalski J. 1988. The microbial environment of the ear canal in health and disease. Vet Clin N Am Small 18: 743-754.

14. Lilenbaum W, Veras M, Blum E, Souza G. 2000. Antimicrobial susceptibility of Staphylococci isolated from otitis externa in dogs. Lett Appl Microbiol 1: 31, 42-45.

15. Merchant $S$. 1997. Medically managing chronic otitis externa and media. Vet Med 92(6): 518-533.

16. Morgan R, Bright R, Swartout M. 2004. Clínica de pequeños animales. $4^{\mathrm{a}}$ ed. Madrid: Elsevier. 1355 p.

17. Oliveira L, Medeiros C, Silva I, Monteiro A, Leite C, Carvalho $C$. 2005. Susceptibilidade a antimicrobianos de bactérias isoladas de otite externa em cães. Arq Bras Med Vet Zootec, Belo Horizonte 57(3): 405-408.

18. Oliveira L, Brilhante R, Cunha A, Carvalho C. 2006. Perfil de isolamento microbiano em cães com otite média e externa associadas. Arq Bras Med Vet Zootec, Fortaleza 58(6): 1009-1017.

19. Pundir S. 2007. Clinic-diagnosis and therapeutic management of bacterial and fungal infections of canine ear with special reference to molecular characterization of certain otic pathogens. Master thesis. Gujarat, India: Anand Agricultural University. 202 p.

20. Taibo R. 2003. Otología: Temas de clínica y cirugía. Buenos Aires: Ed Intermédica. 279 p. 